\title{
Maternal plasma levels of vascular endothelial growth factor and interleukin-6 in the term-pregnant and non-pregnant rats
}

\author{
Mohammed Alotaibi ${ }^{1}$ \\ Department of Physiology, College of Medicine, King Saud University, Riyadh 11461, Kingdom of Saudi Arabia.
}

\begin{abstract}
Female reproductive functions are associated with changes in the level of systemic cytokines which play pivotal roles during ovulation, development of corpus luteum, embryo implantation, and labor. Although many studies reported elevated level of VEGF during early pregnancy and IL- 6 at the onset of labors, there is still incomplete elucidation of the level of these systemic cytokines in the very-late pregnancy or in the non-pregnant states. The purpose of this study was to determine the maternal plasma level of vascular endothelial growth factor (VEGF) and interleukin-6 (IL6 ) in the term-pregnant and non-pregnant rats to see if their levels are changed at the very end of pregnancy. Blood samples were collected from twelve termpregnant rats and compared by aged-matched seven non-pregnant rats. Plasma was separated carefully from all samples and the concentrations of VEGF and IL-6 were determined by ELISA techniques. The plasma concentration of VEGF was significantly higher in the non-pregnant rats $(0.237 \mathrm{pg} / \mathrm{ml})$ than in the termpregnant $(0.2 \mathrm{pg} / \mathrm{ml} ; \mathrm{P}<0.001)$. The plasma concentration of IL-6 was significantly higher in the term-pregnant rats $(50.12 \mathrm{pg} / \mathrm{ml})$ than in the nonpregnant ones $(40.19 \mathrm{pg} / \mathrm{ml} ; \mathrm{P}<0.05)$. These findings suggest that the level of VEGF is decreased few days before labor possibly to decrease the ovarian blood flow and to cause luteolysis while the level of IL-6 is increased at the end of pregnancy possibly to cause a local inflammation. Together, these changes are necessary to stimulate the onset of labor.
\end{abstract}

Keywords: luteolysis, non-pregnant, plasma, termpregnant, VEGF, IL-6.

\section{Introduction}

Normal pregnancy is associated with a local inflammatory response and elevated levels of local inflammatory cytokines which can be detected in maternal systemic circulation (Szarka et al., 2010a). Vascular endothelial growth factor (VEGF) is an angiogenic protein produced by different cell types which exert its action mainly on endothelial cells to promote angiogenesis and vascular permeability (Tjwa et al., 2003). VEGF mediates its activities by interacting with two receptors: fms-like tyrosine kinase-1, Flt-1 (VEGFR-1), and kinase domain-containing region, KDR (VEGFR-2) (Ferrara, 2004). In females, angiogenesis is an important physiological process for the normal development of corpus luteum and endometrium, during menstrual cycle, and during early pregnancy (Smith, 1998; Hickey and Fraser, 2000). It has been reported that the female plasma level of VEGF is fluctuating throughout the menstrual cycle and pregnancy (Lyall et al., 1997; Lygnos et al., 2006). Previous studies have shown that VEGF can be expressed in the endometrium which is necessary for the angiogenesis and vascular permeability in the early implantation of the embryo (Chakraborty et al., 1995; Das et al., 1997). Therefore, VEGF is suggested to play vital roles to provide sufficient blood flow and high vascular permeability for the maintenance of cellular function in corpus luteum during pregnancy (Redmer and Reynolds, 1996). It has been demonstrated in rats that VEGF is expressed in luteal cells during early and mid-pregnancy which is thought to provide luteal angiogenesis and normal development of corpus luteum (Kashida et al., 2001; Pauli et al., 2005). Parturition in rodents such as rats and mice is initiated by luteal regression (luteolysis) and a rapid decline in progesterone circulation (Mitchell and Taggart, 2009; Ratajczak et al., 2010) and it is not clear whether VEGF contributes to the initiation of labor or not, and in this study we measured the plasma level of VEGF in pregnant rats just before the onset of labor. It is known that maternal immune system plays a crucial role during the establishment and maintenance of normal pregnancy and for successful labor (Guerin et al., 2009). In addition, the secretion of cytokines from immune and non-immune cells (e.g. endometrium) is thought to be implicated in the normal reproductive physiology during ovulation (Espey, 1980), embryo implantation (Hess et al., 2007), and labor (Ledingham et al., 2001). One of the most important cytokine is the interleukin-6 (IL-6) which plays an essential role in female reproductive function and initiation of labor (Greig et al., 1997). IL-6 can be secreted from multisource including macrophages, dendritic cells, lymphocytes, and placental trophoblasts (Ishihara and Hirano, 2002; Mohr et al., 2009). It was thought that IL-6 was only secreted from immune cells during inflammation or infection but escalating research confirmed the secretion of IL-6 from different female reproductive tissues such as the placenta, the decidua, the chorion, the amnion, and the endometrium (Bergqvist et al., 2001; Bowen et al., 2002; Turner et al., 2002; Von Wolff et al., 2002; Lockwood et al., 2010). Although previous studies reported elevated level of pro-inflammatory cytokines in human uterine tissues very close to labor (Young et al., 2002), there is still incomplete understanding of the systemic cytokine patterns which may be associated partly with the onset of labor. Therefore, the aim of the present study was to measure the level of plasma VEGF and IL-6 in the non-pregnant and pregnant rats very close to labor. 


\section{Materials and Methods}

Animals

Two groups of female Wistar rats were used in this study and were age-matched. Term-pregnant rats were at their last day of gestation ( $\sim 22$ days) and nonpregnant rats $(\sim 220 \mathrm{~g})$ at their dioestrous stage. Animals were humanely killed by asphyxiation with carbon dioxide $\left(\mathrm{CO}_{2}\right)$ followed by cervical dislocation in accordance with the guidelines and legislations of the animal Care Centre, College of Medicine. All animals were housed in a temperature-controlled room $\left(25^{\circ} \mathrm{C}\right)$ with 12:12-hour dark: light cycles with an average humidity of $25 \%$ and they were all given a standard laboratory chow and ad libitum.

\section{Samples collection}

Soon after decapitation, blood samples were collected from the left ventricle in pre-cooled glass tubes containing EDTA and the plasma was separated by centrifugation at $3,000 \mathrm{~g}$ for $10 \mathrm{~min}$ at $4^{\circ} \mathrm{C}$. The supernatant was immediately removed, snapped frozen and stored at $-80^{\circ} \mathrm{C}$ until analyses were performed.

\section{Quantification of VEGF and IL-6 in plasma}

The stored supernatants were thawed first and centrifuged at 3,000g for $5 \mathrm{~min}$. VEGF and IL-6 were quantitatively assayed by using a high-sensitivity sandwich enzyme-linked immunosorbent assay (ELISA) kits (R\&D Systems, Minneapolis, MN, USA) according to manufacturer's instructions. Internal controls supplied with the kits were used to verify the results with a known concentration of target proteins. A standard curve on the absorbance of VEGF and IL-6 against their concentrations in the standard wells was plotted and the optical density was measured on a microplate reader at $450 \mathrm{~nm}$. Standards and samples were analyzed in duplicates and at the end of experiments they were averaged and expressed as $\mathrm{pg} / \mathrm{ml}$.

\section{Statistical analysis}

Statistical analysis was performed using Originlab Software (v.9.1). The Shapiro-Wilk test was performed to assess the normality of data distribution. Independent student $t$-test was used to analyze the difference of the mean concentrations of VEGF and IL6 between the two groups. Data are presented as mean \pm SEM. $\mathrm{P}<0.05$ was considered significant.

\section{Results}

\section{Descriptive}

Blood were collected successfully from 12 term-pregnant and 7 non-pregnant rats and all animals used in this study were healthy at the time of experiments. The mean age of all animals at the time of experiments was $11 \pm 2$ weeks. All pregnant rats completed their gestation (22 day) with uncomplicated pregnancy and were sacrificed few hours before the onset of labor (parturition in rats occurs anytime between day 22 and day 23). All non-pregnant rats were sacrificed at dioestrous stage by performing daily vaginal smears.

\section{Normality of data}

Shapiro-Wilk test revealed that the data were approximately normally distributed $(\mathrm{P}>0.05)$.

\section{Maternal plasma level of VEGF in non-pregnant and term-pregnant rats}

Using independent student t-test to compare the means of the two groups, the plasma concentration of VEGF was significantly higher in the non-pregnant rats (mean value of $0.237 \pm 0.005 \mathrm{pg} / \mathrm{ml}$ ) than in the termpregnant group (mean value of $0.200 \pm 0.005 \mathrm{pg} / \mathrm{ml}$ ), $\mathrm{P}$ $<0.001$, Fig. 1 .

\section{Maternal plasma level of IL-6 in non-pregnant and term-pregnant rats}

Using independent student t-test compare the means of the two groups, the plasma concentration of IL-6 was significantly higher in the term-pregnant rats (mean value of $50.12 \pm 2.42 \mathrm{pg} / \mathrm{ml}$ ) than in the non-pregnant ones (mean value of $40.19 \pm 3.38$ pg/ml), P $<0.05$, Fig. 2 .

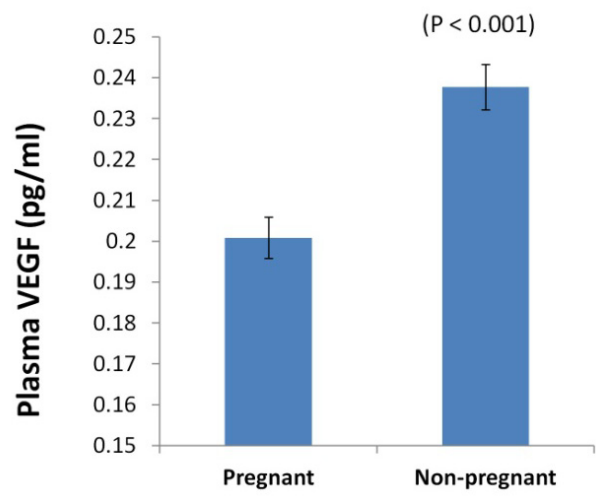

Figure 1. The plasma levels of VEGF in the pregnant and nonpregnant rats. Results are expressed as means $\pm \mathrm{SEM}$.

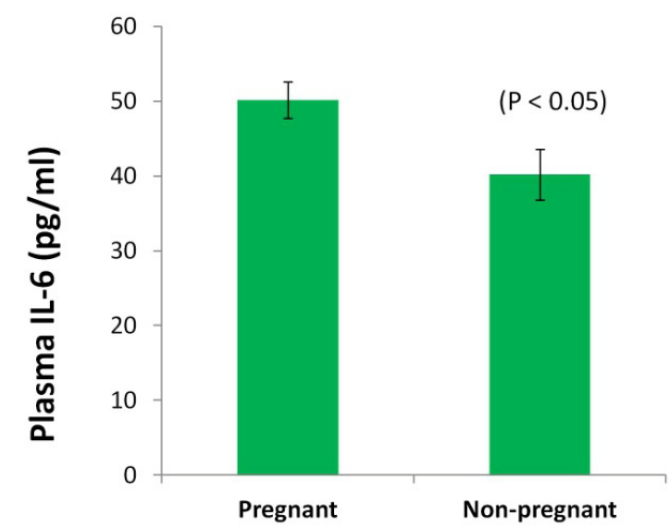

Figure 2. The plasma levels of IL-6 in the pregnant and nonpregnant rats. Results are expressed as means \pm SEM. 


\section{Discussion}

In the present study we VEGF and IL-6 in the plasma of both term-pregnant and non-pregnant rats. The level of VEGF was significantly higher in the plasma of the non-pregnant rats compared to the termpregnant ones. This finding is consistent with previous studies which reported a high serum VEGF in the nonpregnant women than in the normal pregnant women at their third trimester (Lyall et al., 1997). Physiologically, the female reproductive tissues such as the ovarian follicles, the myometrium, and the endometrium, exhibit a dynamic periodic growth and regression throughout the normal menstrual cycle which are associated with periodic changes in blood flow to these tissues. Thus, angiogenesis occurs normally during the development of the follicles, the formation of corpus luteum, and the proliferation and growth of endometrium [for review see (Augustin, 2005) ]. The source of VEGF in female can be originated from different reproductive tissues. It has been reported that VEGF is expressed in the myometrium of the non-pregnant women and the level of VEGF mRNA is higher during the secretory phase of the menstrual cycle (Harrison-Woolrych et al., 1995) than in the proliferative phase. VEGF has also been shown to be expressed in the endometrium (Sugino et al., 2002) probably to increase the endometrial angiogenesis and blood flow which is necessary for the normal proliferation and growth of the endometrium that occurs during the phases of the menstrual cycle. Moreover, VEGF has been demonstrated to be expressed in ovarian corpus luteum to increase the vascular permeability and to maintain the lifespan of corpus luteum and progesterone secretion during pregnancy (Wada et al., 2013). However, during early pregnancy and just before the implantation, the expression of VEGF has been reported to increase dramatically in uterine tissues of both animals and women to ensure and maintain successful pregnancy by increasing the vascular permeability or the formation of dense vascular network around the deciduas (Sugino et al., 2002; Kaczmarek et al., 2009). Therefore, the plasma level of VEGF can be changed throughout the menstrual cycle in the non-pregnant state or during pregnancy depending on the stages of the gestation. Labor in rodents such as rats and mice must be preceded by ovarian luteolysis and a subsequent decrease in circulating progesterone level (Mitchell and Taggart, 2009; Ratajczak et al., 2010). Using Immunohistochemistry, it has been shown in pregnant mice that the expression of VEGF is significantly decreased in corpus luteum at the end of pregnancy followed by a decrease in the circulating progesterone and initiation of labor contractions (Wada et al., 2013) which is in agreement with our data of decreased plasma level of VEGF in termpregnant rats very close to labor (22 day of gestation). Moreover, it has been reported that blocking the VEGF signaling in mice at mid-pregnancy can induce preterm birth (Wada et al., 2013).These studies along with our findings suggest that the physiological decrease in VEGF level at term may impair ovarian blood flow causing luteolysis, regression of deciduas, and eventually resulting in a decrease of circulating progesterone, all of which are necessary for the initiation of labor process.

Normal labor is associated with leukocytes infiltration and increased level of pro-inflammatory cytokines (Bowen et al., 2002; Shynlova et al., 2013) to facilitate and initiate the inflammatory process within the uterine compartments. We found a significant increase in plasma IL-6 in term-pregnant rats very close to labor compared to the non-pregnant ones. This finding is consistent with previous studies which found a higher serum IL-6 in pregnant women who were very close to labor than in the non-pregnant women (Vassiliadis et al., 1998; Szarka et al., 2010b). In addition to IL-6, other pro-inflammatory cytokines such as IL-1 $\beta$, IL-8, and tumor necrosis factor (TNF) have been reported to increase during labor (Young et al., 2002) and the cellular origin of these cytokines includes the cervix, the myometrium, the deciduas, the fetal membranes, and the placenta (Young et al., 2002; Osman et al., 2003). It is thought that the infiltrating leukocytes are the major source of pro-inflammatory cytokines found in the uterine tissues just before or during the onset of labor process (Young et al., 2002). Typically, the level of these cytokines increases few days before the onset of labor, peaks during labor, and declines after labor. The functions of these cytokines in the process of labor remain obscure but it is suggested that during labor these cytokines are responsible for the initiation of a cascade of events including prostaglandin production (Molnár et al., 1993) and recruitment and attraction of additional leukocytes (Osman et al., 2003). This would further amplify the inflammatory process within the intrauterine tissues and hasten the rupture of membrane resulting in initiation of uterine contractions. Another function of pro-inflammatory cytokines is the synthesis of matrix metalloproteinases (collagenase enzymes capable of degrading extracellular matrix macromolecules and collagens) and it has been shown that IL-6 can induce the MMPs in immune cells (Kothari et al., 2014). Furthermore, the level of proinflammatory cytokines including IL-6 was found to be upregulated in human cervical tissues during the ripening process to facilitate the cervical remodeling and effacement (Sennström et al., 2000). Therefore, the cascades of inflammatory cytokines-induced labor might be one of several important mechanisms leading to the onset of labor. Another suggested mechanism of labor which might be critical for the endocrine control of labor is the link between functional withdrawal of progesterone and the functional activation of estrogen (Mesiano, 2004). The increased responsiveness of the uterus to estrogen, increased expression of myometrial oxytocin receptors, increased myometrial/cervical stretching, stimulation of uterine tissues by the fetus, and the recruitment of inflammatory cytokines can all contribute to transform the uterus from a relatively quiescent to a contractile and excitable tissue resulting in the initiation of labor.

In conclusion, in this study we report that the plasma level of VEGF is decreased in late-pregnancy indicating that VEGF could be involved in the 
prolongation of the lifespan of corpus luteum for successful pregnancy and as labor approaches the level of VEGF decreases. We also report an increased plasma level of IL-6 in term-pregnant rats very close to labor, and this may be important to facilitate and initiate the process of labor. In addition, the expression and the level of pro-inflammatory cytokines are vital for successful labor and any alteration of their systemic level may lead to maternal complications. Further studies are required to elucidate the mechanism(s) leading to the reduction in the concentration of VEGF before the onset of labor and to investigate other proinflammatory cytokines in maternal reproductive tissues before and after the onset of labor, as these would further increase our current understanding of the physiology of labor and angiogenesis.

\section{References}

Augustin HG. 2005. Angiogenesis in the female reproductive system. In: Clauss M, Breier G (Ed.). Mechanisms of Angiogenesis. Basel, Switzerland: Birkhäuser Basel. pp.35-52

Bergqvist A, Bruse C, Carlberg MCarlström K. 2001. Interleukin $1 \beta$, interleukin-6, and tumor necrosis factor- $\alpha$ in endometriotic tissue and in endometrium. Fertil Steril, 75:489-495.

Bowen J, Chamley L, Mitchell MKeelan J. 2002. Cytokines of the placenta and extra-placental membranes: biosynthesis, secretion and roles in establishment of pregnancy in women. Placenta, 23:239-256.

Chakraborty I, Das SDey S. 1995. Differential expression of vascular endothelial growth factor and its receptor mRNAs in the mouse uterus around the time of implantation. J Endocrinol, 147:339-352.

Das S, Chakraborty I, Wang J, Dey SHoffman L. 1997. Expression of vascular endothelial growth factor (VEGF) and VEGF-receptor messenger ribonucleic acids in the peri-implantation rabbit uterus. Biol Reprod, 56:1390-1399.

Espey LL. 1980. Ovulation as an inflammatory reaction-a hypothesis. Biol Reprod, 22:73-106.

Ferrara N. 2004. Vascular endothelial growth factor: basic science and clinical progress. Endocr Rev, 25:581611.

Greig PC, Murtha AP, Jimmerson CJ, Herbert WN, Roitman-Johnson BAllen J. 1997. Maternal serum interleukin-6 during pregnancy and during term and preterm labor. Obstet Gynecol, 90:465-469.

Guerin LR, Prins JRRobertson SA. 2009. Regulatory T-cells and immune tolerance in pregnancy: a new target for infertility treatment? Hum Reprod Update, 15:517-535.

Harrison-Woolrych ML, Sharkey AM, CharnockJones DSmith S. 1995. Localization and quantification of vascular endothelial growth factor messenger ribonucleic acid in human myometrium and leiomyomata. J Clin Endocrinol \& Metab, 80:1853-1858. Hess A, Hamilton A, Talbi S, Dosiou C, Nyegaard M, Nayak N, Genbecev-Krtolica $O$, Mavrogianis $P$, Ferrer KKruessel J. 2007. Decidual stromal cell response to paracrine signals from the trophoblast: amplification of immune and angiogenic modulators. Biol Reprod, 76:102-117.

Hickey MFraser I. 2000. The structure of endometrial microvessels. Hum Reprod, 15:57-66.

Ishihara KHirano T. 2002. IL-6 in autoimmune disease and chronic inflammatory proliferative disease. Cytokine Growth Factor Rev, 13:357-368.

Kaczmarek M, Kiewisz J, Schams DZiecik A. 2009. Expression of VEGF-receptor system in conceptus during peri-implantation period and endometrial and luteal expression of soluble VEGFR-1 in the pig. Theriogenology, 71:1298-1306.

Kashida S, Sugino N, Takiguchi S, Karube A, Takayama H, Yamagata $Y$, Nakamura YKato $H$. 2001. Regulation and role of vascular endothelial growth factor in the corpus luteum during midpregnancy in rats. Biol Reprod, 64:317-323.

Kothari P, Pestana R, Mesraoua R, Elchaki R, Khan KF, Dannenberg AJFalcone DJ. 2014. IL-6-mediated induction of matrix metalloproteinase- 9 is modulated by JAK-dependent IL-10 expression in macrophages. $J$ Immunol, 192:349-357.

Ledingham M, Thomson A, Jordan F, Young A, Crawford MNorman J. 2001. Cell adhesion molecule expression in the cervix and myometrium during pregnancy and parturition. Obstet Gynecol, 97:235-242.

Lockwood CJ, Murk WK, Kayisli UA, Buchwalder LF, Huang SJ, Arcuri F, Li M, Gopinath ASchatz F. 2010. Regulation of interleukin-6 expression in human decidual cells and its potential role in chorioamnionitis. Am J Pathol, 177:1755-1764.

Lyall F, Greer IA, Boswell FFleming R. 1997. Suppression of serum vascular endothelial growth factor immunoreactivity in normal pregnancy and in pre-eclampsia. BJOG, 104:223-228.

Lygnos M, Pappa K, Papadaki H, Relakis C, Koumantakis E, Anagnou NEliopoulos G. 2006. Changes in maternal plasma levels of VEGF, bFGF, TGF- $\beta 1$, ET-1 and sKL during uncomplicated pregnancy, hypertensive pregnancy and gestational diabetes. In Vivo, 20:157-163.

Mesiano S. 2004. Myometrial progesterone responsiveness and the control of human parturition. $J$ Soc Gynecol Investig, 11:193-202.

Mitchell BFTaggart MJ. 2009. Are animal models relevant to key aspects of human parturition? $\mathrm{Am} J$ Physiol Regul Integr Comp Physiol, 297:R525-R545.

Mohr E, Serre K, Manz RA, Cunningham AF, Khan M, Hardie DL, Bird RMacLennan IC. 2009. Dendritic cells and monocyte/macrophages that create the IL-6/APRIL-rich lymph node microenvironments where plasmablasts mature. J Immunol, 182:2113-2123. Molnár M, Romero RHertelendy F. 1993. Interleukin-1 and tumor necrosis factor stimulate arachidonic acid release and phospholipid metabolism in human myometrial cells. Am J Obstet Gynecol, 169:825-829.

Osman I, Young A, Ledingham MA, Thomson AJ, Jordan F, Greer IANorman JE. 2003. Leukocyte density and pro-inflammatory cytokine expression in human fetal membranes, decidua, cervix and myometrium before and during labour at term. Mol 
Hum Reprod, 9:41-45.

Pauli SA, Tang H, Wang J, Bohlen P, Posser R, Hartman T, Sauer MV, Kitajewski JZimmermann RC. 2005. The vascular endothelial growth factor (VEGF)/VEGF receptor 2 pathway is critical for blood vessel survival in corpora lutea of pregnancy in the rodent. Endocrinology, 146:1301-1311.

Ratajczak CK, Fay JCMuglia LJ. 2010. Preventing preterm birth: the past limitations and new potential of animal models. Dis Model Mech, 3:407-414.

Redmer DAReynolds LP. 1996. Angiogenesis in the ovary. Rev Reprod, 1:182-192.

Sennström MB, Ekman G, Westergren-Thorsson G, Malmström A, Byström B, Endrésen U, Mlambo N, Norman M, Ståbi BBrauner A. 2000. Human cervical ripening, an inflammatory process mediated by cytokines. Mol Hum Reprod, 6:375-381.

Shynlova O, Nedd-Roderique T, Li Y, Dorogin ALye SJ. 2013. Myometrial immune cells contribute to term parturition, preterm labour and post-partum involution in mice. J Cell Mol Med, 17:90-102.

Smith S. 1998. Angiogenesis, vascular endothelial growth factor and the endometrium. Hum Reprod Update, 4:509-519.

Sugino N, Kashida S, Karube-Harada A, Takiguchi SKato H. 2002. Expression of vascular endothelial growth factor (VEGF) and its receptors in human endometrium throughout the menstrual cycle and in early pregnancy. Reproduction, 123:379-387.

Szarka A, Rigó J, Lázár L, Bekő GMolvarec A. 2010a. Circulating cytokines, chemokines and adhesion molecules in normal pregnancy and preeclampsia determined by multiplex suspension array. BMC
Immunol, 11:1.

Szarka A, Rigó J, Lázár L, Bekő GMolvarec A. 2010b. Circulating cytokines, chemokines and adhesion molecules in normal pregnancy and preeclampsia determined by multiplex suspension array. BMC Immunol, 11:59.

Tjwa M, Luttun A, Autiero MCarmeliet P. 2003. VEGF and PIGF: two pleiotropic growth factors with distinct roles in development and homeostasis. Cell Tissue Res, 314:5-14.

Turner M, Shaikh SGreenwood S. 2002. Secretion of interleukin-1 $\beta$ and interleukin- 6 by fragments of Term Human Placental Villi: Signalling Pathways and effects of Tumour Necrosis factor $\alpha$ and Mode of Delivery. Placenta, 23:467-474.

Vassiliadis S, Ranella A, Papadimitriou L, Makrygiannakis AAthanassakis I. 1998. Serum levels of pro-and anti-inflammatory cytokines in non-pregnant women, during pregnancy, labour and abortion. Mediators Inflamm, 7:69-72.

Von Wolff M, Thaler C, Zepf C, Becker V, Beier HStrowitzki T. 2002. Endometrial expression and secretion of interleukin-6 throughout the menstrual cycle. Gynecol Endocrinol, 16:121-129.

Wada Y, Ozaki H, Abe N, Mori A, Sakamoto K, Nagamitsu T, Nakahara TIshii K. 2013. Role of vascular endothelial growth factor in maintenance of pregnancy in mice. Endocrinology, 154:900-910.

Young A, Thomson AJ, Ledingham M, Jordan F, Greer IANorman JE. 2002. Immunolocalization of proinflammatory cytokines in myometrium, cervix, and fetal membranes during human parturition at term. Biol Reprod, 66:445-449. 